\title{
Thermal Stability of Phaseolus vulgaris Leucoagglutinin: a Differential Scanning Calorimetry Study
}

\author{
Shyamasri Biswas and Arvind M. Kayastha* \\ School of Biotechnology, Faculty of Science, Banaras Hindu University, Varanasi-221 005, India
}

Received 18 July 2002, Accepted 2 August 2002

\begin{abstract}
Phaseolus vulgaris phytohemagglutinin $\mathrm{L}$ is a homotetrameric-leucoagglutinating seed lectin. Its threedimensional structure shows similarity with other members of the legume lectin family. The tetrameric form of this lectin is $\mathrm{pH}$ dependent. Gel filtration results showed that the protein exists in its dimeric state at $\mathrm{pH} 2.5$ and as a tetramer at pH 7.2. Contrary to earlier reports on legume lectins that possess canonical dimers, thermal denaturation studies show that the refolding of phytohemagglutinin $\mathrm{L}$ at neutral $\mathrm{pH}$ is irreversible. Differential scanning calorimetry (DSC) was used to study the denaturation of this lectin as a function of $\mathrm{pH}$ that ranged from 2.0 to 3.0. The lectin was found to be extremely thermostable with a transition temperature around $82^{\circ} \mathrm{C}$ and above $100^{\circ} \mathrm{C}$ at $\mathrm{pH} 2.5$ and 7.2, respectively. The ratio of calorimetric to vant Hoff enthalpy could not be calculated because of its irreversiblefolding behavior. However, from the DSC data, it was discovered that the protein remains in its compact-folded state, even at $\mathrm{pH} 2.3$, with the onset of denaturation occurring at $60^{\circ} \mathrm{C}$.
\end{abstract}

Keywords: Differential scanning calorimetry, Phaseolus vulgaris leucoagglutinin, Plant lectins, Transition temperature

\section{Introduction}

Lectins are proteins of non-immune origin that bind carbohydrates in a reversible and specific manner, and often have hemagglutinating properties. Legume lectins are the model system of choice to study the molecular basis of these recognition events, because they are not only easy to purify in large quantities, but they also exhibit a wide variety of carbohydrate specificity, despite a strong sequence

*To whom correspondence should be addressed.

Tel: 91-542-368331; Fax: 91-542-368693

E-mail: kayastha@epatra.com conservation (Sharon and Lis, 1990). Phaseolus vulgaris leucoagglutinin (PHAL) is a complex carbohydrate specific lectin that possesses the canonical legume lectin dimer (Loris et al., 1998). The canonical mode of dimerization is characterized by the antiparallel side-by-side alignment of two 6-stranded beta sheets, one from each monomer, which produces a continuous 12-stranded sheet. PHAL has two such dimers that are associated to form a homotetramer (Hamelryck et al., 1996). PHAL has been used extensively as a lymphocyte-agglutinating agent as it binds to glycosidic receptors on lymphocyte surface membranes (Serafini, 1980). The exact role of PHAL in plants is still unclear, although a possible role in plant defense has been proposed (Chrispeels and Raikhel, 1991). It has been proposed that phytohemagglutinin binds to glycoproteins in the intestinal mucosa of mammals and insects, and that its toxicity is a result of this initial binding. This protects seeds from being eaten by mammals, or being infested by bruchid larvae that burrow into seeds (Pusztai, 1993). Although PHAL has been extensively used for hemagglutinating studies, there are no reports on the stability and folding of this protein. Thermal denaturation studies will enable one to understand the amount of thermal stress the protein can withstand inside the seed.

Current thermodynamic studies on Con A (Schwarz et al., 1993), pea seed lectin (Manoj et al., 2000), lentil lectin (Schwarz et al., 1993), and tetrameric peanut agglutinin (Reddy et al., 1999) show that the folding process in these proteins are reversible and cooperative. In the present communication, differential scanning calorimetry (DSC) was used to study the thermal denaturation of the kidney bean (Phaseolus vulgaris) leucoagglutinin as a function of $\mathrm{pH}$ that ranges from 2 to 3 . The DSC result at $\mathrm{pH} 7.2$ showed that thermal denaturation of this protein was an irreversible process that contradicts earlier reports on legume lectins that possess the canonical dimers.

\section{Materials and Methods}

PHAL (Purified) was purchased from the Sigma Chemical Co. (St. 
Louis, USA) Glycine, sodium chloride, calcium chloride, and manganese chloride were purchased from Merck (Darmstadt, Germany). Molecular weight markers for gel filtration were purchased from Amersham Pharmacia Biotech (Uppsala, Sweden). MOPS was from Fluka Biochemica (Germany). All of the other chemicals were from Merck (Darmstadt, Germany). All of the solutions were prepared by using millipore water.

Gel-filtration studies The gel-filtration of the protein was carried out by analytical gel-filtration on the Superdex 75 HR 10/30 column, Amersham Pharmacia Biotech (Uppsala, Sweden). Ovalbumin (46,300), Aldolase (172,000), Chymotrypsinogen $(20,700)$, Ferritin $(418,000)$, and Ribonuclease $(15,700)$ were used for calibrating the column (data not shown). The flow rate was maintained at $0.5 \mathrm{ml} / \mathrm{min}$ for all of the protein runs. The protein that was incubated at $\mathrm{pH} 2.5$ and 7.2 was run through the same column, and the elution pattern was observed at these $\mathrm{pHs}$.

Preparation of buffers The glycine- $\mathrm{HCl}$ buffer $10 \mathrm{mM}$ at $\mathrm{pH} 2$, 2.3, 2.5, 2.7, and 3 were prepared for scans in the acidic range. Ten $\mathrm{mM}$ MOPS that contained $1 \mathrm{mM} \mathrm{CaCl}, 1 \mathrm{mM} \mathrm{MnCl}_{2}$, and $15 \mathrm{mM}$ $\mathrm{NaCl}$ was used for protein at $\mathrm{pH}$ 7.2.

Protein-concentration determination The protein concentration was determined prior to each scan by monitoring its UV absorption value at $280 \mathrm{~nm}$ using its extinction coefficient, as described previously by Pace et al. (1995). The extinction coefficient of the denatured protein was obtained from the GCG data bank from the amino acid composition of the protein. The extinction coefficient of the native protein was calculated using the Edelhoc method (Edelhoc, 1967). Since the extinction coefficient of the native protein had only a small difference with the denatured one, the extinction coefficient value of the denatured protein $\left(34850 \mathrm{M}^{-1}\right.$ $\mathrm{cm}^{-1}$ ) was taken to determine the protein concentration for all of the experiments.

DSC measurements All of the measurements were performed using a Microcal VP-DSC heat-conduction microcalorimeter (Northampton, MA, USA), which consisted of two fixed cells, a reference cell, and a sample cell. Prior to all the measurements the buffers and protein solutions were degassed, and the protein was dialyzed against respective buffers overnight. The protein concentrations at different $\mathrm{pHs}, 2.0,2.3,2.5,2.7$, and 3.0 were $0.295 \mathrm{mg} / \mathrm{ml}, \quad 0.214 \mathrm{mg} / \mathrm{ml}, \quad 0.338 \mathrm{mg} / \mathrm{ml}, \quad 0.325 \mathrm{mg} / \mathrm{ml}$, and $0.29 \mathrm{mg} / \mathrm{ml}$, respectively.

Several buffer runs were performed in order to get a good baseline; the protein was run only after a good baseline was obtained. The scan rate at each $\mathrm{pH}$ was $60 \mathrm{k} / \mathrm{h}$. At pH 2.5, two runs were performed using a scan rate of 60 and $90 \mathrm{k} / \mathrm{h}$.

Data analysis All of the data were analyzed using the ORIGIN DSC software that was provided by Microcal Inc. (Northampton, USA).

\section{Results and Discussion}

The molecular mass of the protein was determined by analytical gel filtration. It was observed that the protein exists

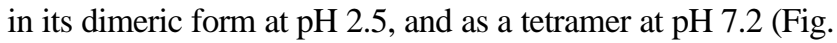
1). The transformation of the tetramer to dimer takes place as soon as the $\mathrm{pH}$ is brought down from $\mathrm{pH} 7.2$ to 2.5 ; it remained in this form, even after two weeks of incubation at this $\mathrm{pH}$ (Biswas, 2002). From the calibration curve, the molecular weight at $\mathrm{pH} 2.5$ and 7.2 were found to be approximately 56,000 and 114,000, respectively (data not shown).

In order to make the conditions of the experiment more physiological, a DSC scan at neutral $\mathrm{pH}$ was carried out in the presence of salts. However, it was discovered that the manganese salt resulted in the formation of brown-colored oxide at higher temperatures. This could damage the cells of the instrument. Hence, while performing runs at lower $\mathrm{pH}$, the presence of salt in the buffer was avoided. It was also observed that the melting temperature at neutral $\mathrm{pH}$ was above $100^{\circ} \mathrm{C}$. Also, when the protein was cooled and reheated, because of severe aggregation, there was an unusual downward slope in the reheating thermogram (see Fig. 4).

The DSC scans that were performed at varying $\mathrm{pH}$ showed irreversible thermal denaturation (Fig. 2). There was a sharp increase in the melting temperature with the rise in $\mathrm{pH}$. At $\mathrm{pH}$ 2.0, the curve ended with a downward slope, and the peak area could not be calculated. The temperature maximum of the curves increased with an increase in $\mathrm{pH}$. An overview of the melting temperature at different $\mathrm{pH}$ is given in Table 1 .

All of the curves that were observed at different $\mathrm{pH}$ had an asymmetric peak. A gradual rise in the heat capacity values was observed at the onset of denaturation, which resulted in a sharp fall in the values after the peak maximum was reached. The increase in the scan rate from 60 to $90 \mathrm{k} / \mathrm{h}$ also resulted in

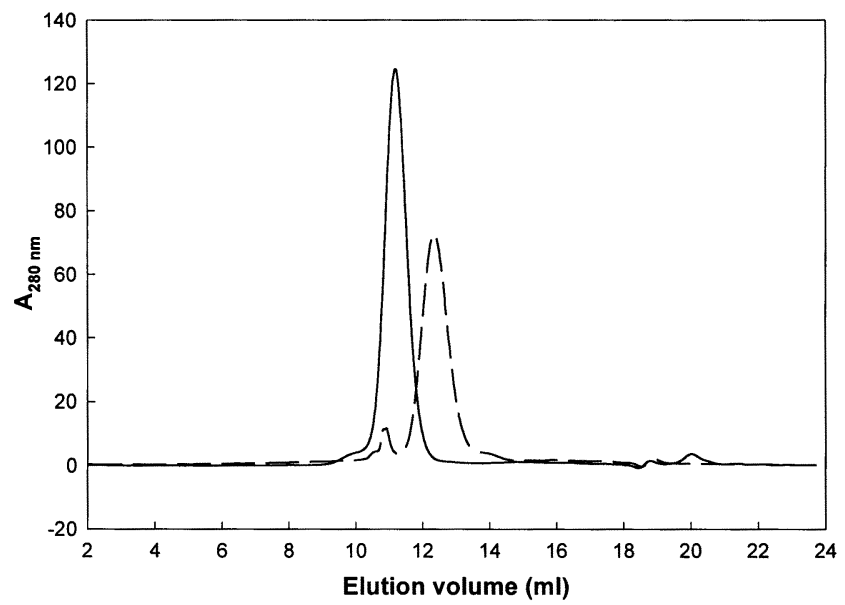

Fig. 1. Elution pattern of PHAL at two different $\mathrm{pH}$. PHAL that was kept at $\mathrm{pH} 2.5$ (broken line) for two days was eluted after the protein was incubated at $\mathrm{pH} 7.2$ (solid line). From the calibration curve of the column, it was found that the protein exists in its dimeric form at $\mathrm{pH} 2.5$ and in its tetrameric form at $\mathrm{pH}$ 7.2. The protein concentrations in this experiment were $1.64 \mathrm{mg} / \mathrm{ml}(\mathrm{pH} 7.2)$ and $1.14 \mathrm{mg} / \mathrm{ml}(\mathrm{pH} 2.5)$. 


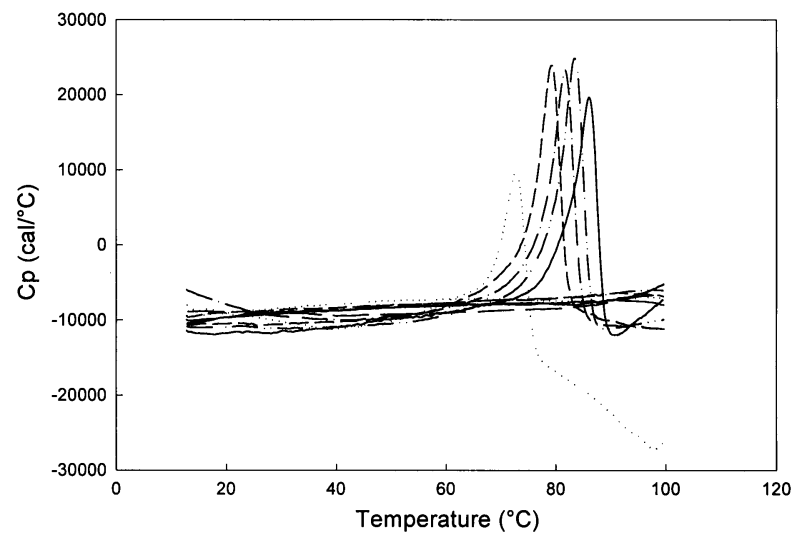

Fig. 2. DSC scans with $\mathrm{PHAL}$ from 10 to $100^{\circ} \mathrm{C}$ at $\mathrm{pH} 2.0$ (dotted line), 2.3 (dashed line), 2.5 (dashed dotted line), 2.7 (dashed double dotted line), and 3.0 (solid line). The reheating at all of the above $\mathrm{pH}$ are shown in different patterns of black lines. The scan rate was $60 \mathrm{k} / \mathrm{h}$.

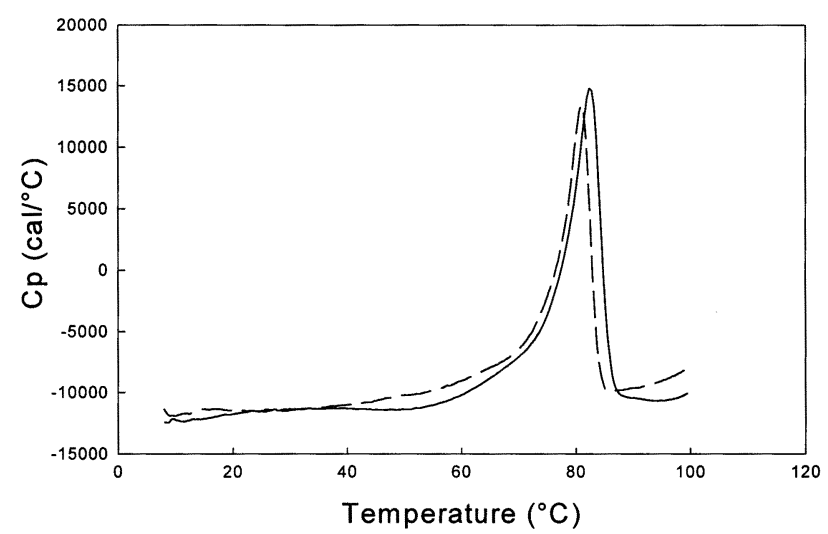

Fig. 3. DSC scans with two different scan rates of PHAL at $\mathrm{pH}$ 2.5 with scan rats $60 \mathrm{k} / \mathrm{h}$ (broken line) and $90 \mathrm{k} / \mathrm{h}$ (solid line). The melting temperature with scan rates $60 \mathrm{k} / \mathrm{h}$ and $90 \mathrm{k} / \mathrm{h}$ were $81.15^{\circ} \mathrm{C}$ and $82.4^{\circ} \mathrm{C}$, respectively.

an increase in the peak maximum value at $\mathrm{pH} 2.5$, which showed evidence of irreversibility in the folding-unfolding behavior of the protein (Fig. 3). All of the curves were normalized with respect to the protein concentration. A DSC scan at $\mathrm{pH} 7.2$ produced a peak maximum value, which was above $100^{\circ} \mathrm{C}$ (Fig. 4). This proved that the protein is extremely stable at neutral $\mathrm{pH}$.

The calorimetric recordings of the lectin samples allowed no unambiguous integration. To obtain rough estimates of the enthalpy values from the peak area, the following procedure was applied. After subtraction of the buffer baseline and concentration normalization, a baseline was constructed that connected the heat capacity value at $50^{\circ} \mathrm{C}$ with the end of the melting peak using cubic splines. The resulting peak areas are given in Table 1.

Incubation of the proteins at an acidic $\mathrm{pH}$ can have a wide range of conformational consequences. Contrary to earlier

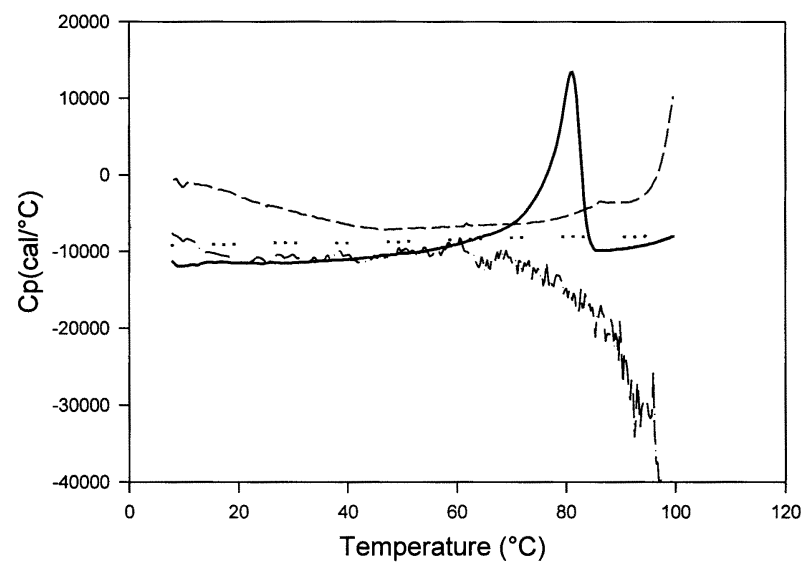

Fig. 4. DSC scans from 10 to $100^{\circ} \mathrm{C}$ with $\mathrm{PHAL}$ at $\mathrm{pH} 2.5$ (solid line), $\mathrm{pH} 7.2$ (broken line) reheating at $\mathrm{pH} 2.5$ (dotted line), and reheating at $\mathrm{pH} 7.2$ (dash dotted line). The scan rate was $60 \mathrm{k} / \mathrm{h}$.

Table 1. Melting temperature and enthalpy values of PHAL at different $\mathrm{pH}$

\begin{tabular}{ccc}
\hline $\mathrm{pH}$ & $\begin{array}{c}\text { Temperature } \\
\text { Maxima }\left({ }^{\circ} \mathrm{C}\right)\end{array}$ & Area $(\mathrm{kcal} / \mathrm{mol})$ \\
\hline 2.0 & 73 & n.d. ${ }^{*}$ \\
2.3 & 79.4 & 260 \\
2.5 & 81.8 & 250 \\
2.7 & 83.4 & 280 \\
3.0 & 86.08 & 240 \\
\hline
\end{tabular}

*n.d. (not determined)

reports (Loris et al., 1998), it was discovered that the conformation of PHAL was $\mathrm{pH}$ dependent. Gel-filtration results proved that the protein existed in its dimeric form at

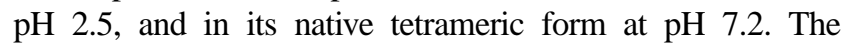
explanation of this phenomenon lies in its three-dimensional structure (Hamelryck et al., 1996). Each monomer of PHAL was involved in two different monomer-monomer interfaces. The first interface was a conventional $\beta$ sheet-like contact between two polypeptides that created a continuous antiparallel 12-stranded beta sheet; the other interface was mainly formed by a van der Waals interaction between two dimers. In the tetramer, the two-curved 12-strand $\beta$-sheet faced each other, which created a large channel between them. Therefore, although the change in $\mathrm{pH}$ was strong enough to break away the weak non-covalent bonds between the two dimers, it could not break the hydrogen bonds between the continuous beta sheets.

The protein showed remarkable thermostability (i.e., a thermal transition at about $80^{\circ} \mathrm{C}$ at $\mathrm{pH} 2.3$ ), which suggests an existing compact-protein structure in the acidic $\mathrm{pH}$ range. However, the thermal transition was irreversible and accompanied by visible aggregation. The protein was also extremely thermostable at neutral $\mathrm{pH}$ with the onset of denaturation at $80^{\circ} \mathrm{C}$ and transition temperature above $100^{\circ} \mathrm{C}$. 
The peak maximum temperature was scan-rate dependent, which is typical for protein unfolding, including the irreversible denaturation step (Sanchez-Ruiz, 1995). Accordingly, the roughly-estimated denaturation enthalpy values that are listed in Table 1 must be taken with great caution.

The thermodynamic studies on Phaseolus vulgaris leucoagglutinin appeared to be quite different from previous studies on peanut agglutinin (Reddy et al., 1999), Con A (Schwarz et al., 1993), pea seed (Schwarz et al., 1993; Manoj et al., 2000), and lentil lectin (Schwarz et al., 1993), although all of them are composed of canonical dimers and are members of the legume lectin family. The melting temperature of legume lectins that has been reported was below $100^{\circ} \mathrm{C}$ [e.g., thermodynamic studies on peanut agglutinin, a homotetrameric legume lectin (Reddy et al., 1999)], which shows that the unfolding process is reversible. It has been described by a three-state model with two transitions that occurred at 58 and $68^{\circ} \mathrm{C}$. In contrast to these findings, thermal unfolding of leucoagglutinin at neutral $\mathrm{pH}$ is an irreversible process. Heat effect on the protein alone cannot explain its folding-unfolding behavior. Because of its irreversible nature, the ratio of $\Delta \mathrm{H}_{\mathrm{c}} / \Delta \mathrm{H}_{\mathrm{v}}$ cannot be compared with other lectins.

Acknowledgments The financial assistance from the Council of Scientific Research, New Delhi (Junior Research Fellowship to S.B.) and DAAD (Sandwich Model Fellowship to S.B.) to carry out a part of the research work in Germany is thankfully acknowledged. We are grateful to Professors R. Seckler and W. Pfeil, Physical Biochemistry Laboratory, University of Potsdam, Golm, Germany, for providing the necessary laboratory facilities and helpful discussion.

\section{References}

Biswas, S. (2002) Biophysical studies on $\beta$-galactosidase and lymphocyte agglutinating lectin from kidney beans (Phaseolus vulgaris). Ph.D. Dissertation, Banaras Hindu University, Varanasi, pp. 1-138.

Chrispeels, M. J. and Raikhel, N. V. (1991) Lectins, lectin genes, and their roles in plant defense. Plant Cell 3, 1-9.

Edelhoch, H. (1967) Spectroscopic determination of tryptophan and tyrosine in proteins. Biochemistry 6, 1948-1954.

Hamelryck, T. W., Dao-Thi, M., Poortmans, F., Chrispeels, M. J., Wyns, L. and Loris, R. (1996) The crystallographic structure of phytohemagglutinin-L. J. Biol. Chem. 271, 20479-20485.

Loris, R., Hamelryck, T. W., Bouckaert, J. and Wyns, L. (1998) Legume lectin structure. Biochim. Biophys. Acta 1383, 9-36.

Manoj, N., Srinivas, V. R., Surolia, A., Vijayan, M. and Suguna, K. (2000) Carbohydrate specificity and salt bridge mediated conformational change in acidic winged bean agglutinin. $J$. Mol. Biol. 302, 1129-1137.

Pace, C. N., Vajdos, F., Fee, L., Grimsley, G. and Gray, T. (1995) How to measure and predict the molar absorption coefficient of a protein. Protein Sci. 4, 2411-2423.

Pusztai, A. (1993) Dietary lectins are metabolic signals for the gut and modulate immune and hormone functions. Eur. J. Clin. Nutr. 47, 691-699.

Reddy, G. B., Bharadwaj, S. and Surolia, A. (1999) Thermal stability and mode of oligomerization of the tetrameric peanut agglutinin: A differential scanning calorimetry study. Biochemistry 38, 4464-4470.

Sanchez-Ruiz, J. M. (1995) Differential scanning calorimetry of proteins. Subcell. Biochem. 24, 133-76.

Schwarz, F. P., Puri, K. D., Bhat, R. G. and Surolia, A. (1993) Thermodynamics of monosaccharides binding to Concavalin A, Pea (Pisum sativum) lectin and lentil (Lens culinaris) lectin. J. Biol. Chem. 268, 7668-7677.

Serafini-Cess, F. Montanaro, L. and Sperti, S. (1980) Effect of temperature on haemagglutinating activity and on the conformation of leucoagglutinin, a lectin from Phaseolus vulgaris (red kidney bean). FEBS Lett. 120, 115-118.

Sharon, N. and Lis, H. (1990) Legume lectins- a large family of homologous proteins. FASEB J. 4, 3198-3208. 